\title{
Genetic control of stiffness of standing Douglas fir; from the standing stem to the standardised wood sample, relationships between modulus of elasticity and wood density parameters. Part II
}

\author{
Philippe Rozenberg*, Alain Franc, Cécile Mamdy, Jean Launay, \\ Nicolas Schermann, Jean Charles Bastien
}

Inra Orléans, 45160 Ardon, France

(Received 18 December 1997; accepted 1 October 1998)

\begin{abstract}
Fairly strong positive relationships between stiffness and density have often been reported. No stronger relationships have been found when using parameters of density profiles based on an earlywood-latewood boundary. In this study, we attempt to model the relationships among the stiffness of different samples and simple parameters derived from microdensity profiles, not established according to an earlywood-latewood boundary. Furthermore, we try to determine if there is a genetic variation for the relationship between stiffness and density. From the results, we find that the strongest relationship between a single density parameter and stiffness is $r^{2}=0.78$, whereas it is $r^{2}=0.37$ when involving a classical within-ring density parameter. At clone level, $r^{2}$ ranges from 0.88 to 0.95 , while it is 0.51 for the bulked samples. The mathematical form of the models differ from one clone to another: there is a genetic effect on the models. This could mean that different clones different build their stiffness in different ways. (C Inra/Elsevier, Paris.)
\end{abstract}

genetics / modulus of elasticity / wood density / X-ray microdensitometry / Douglas fir

Résumé - Modélisation du module d'élasticité à l'aide de données microdensitométriques : méthodes et effets génétiques. $2^{e}$ partie. On a souvent mis en évidence d'assez fortes relations entre la rigidité et la densité du bois. Ces relations n'étaient pas plus fortes quand on a essayé d'expliquer la rigidité à l'aide de paramètres microdensitométriques intra-cerne basés sur une limite bois initial-bois final. Dans cette étude, nous tentons de modéliser la rigidité d'un échantillon de bois à l'aide de paramètres simples calculés à partir de profils microdensitométriques, mais non basés sur la limite classique bois initial-bois final. De plus, nous cherchons si les modèles décrivant cette relation sont différents d'une unité génétique à l'autre. Les résultats montrent que les modèles bâtis à l'aide de nos nouveaux paramètres sont plus précis que ceux construits à l'aide des paramètres intra-cernes classiques (par exemple, pour les mêmes échantillons, $\mathrm{r}^{2}$ passe de 0,37 à 0,78 quand la rigidité est expliquée à l'aide d'un de ces nouveaux paramètres, plutôt qu'à l'aide de la densité du bois final). Au niveau clonal, le $r^{2}$ varie de 0,88 à 0,94 , alors que tous échantillons confondus, il est seulement de 0,51 . De plus, la forme mathématique des modèles est différente d'un clone à l'autre. Donc il existe un effet génétique sur la relation rigidité-densité. Si ces résultats sont confirmés, cela signifie que différents clones ont différentes manières de construire leur rigidité. (C Inra/Elsevier, Paris.)

génétiques / module d'élasticité / densité du bois / microdensité aux rayons $X$ / douglas

* Correspondence and reprints

rozenberg@orleans.inra.fr 


\section{INTRODUCTION}

Since the end of the nineteenth century, density has been acknowledged as the best single predictor of wood mechanical properties [1, 15, 20-22, 33]. Modulus of elasticity (MOE), or stiffness, is a basic mechanical property for softwoods, especially when they are used as solid wood products in structure $[8,20]$. The first part of this report presents a non-destructive tree-bending machine, the modulometre, which is similar to the device elaborated by Koizumi and Ueda [13] and used to measure the stiffness of standing tree trunks (trunk MOE).

Fairly strong positive relationships between MOE and specific gravity of samples of different shapes and sizes have often been reported: e.g. on standard wood samples of Pseudotsuga menziesii (coefficient of determination $r^{2}=0.64$ [15]), Pinus yunnanensis $\left(r^{2}=0.73\right.$ [30]), Picea koraiensis $\left(r^{2}=0.50[30]\right)$, Larix decidua $\left(r^{2}=0.52\right.$ [23]), on small uniform within-ring wood samples of Picea abies $\left(r^{2}=0.83\right.$ [4]) and on mini-bending samples of Pseudotsuga menziesii ( $r^{2}=0.67$ [25]). On Picea abies standard wood sample, de Reboul [9] found that $r^{2}$ could reach 0.76 .

As wood properties and wood anatomy are intimately related $[7,11,24,32]$, some researchers tried to correlate the MOE and some within-ring density parameters computed from density profiles (like X-ray density profiles [24]). They did not found more satisfying relationships than those between the MOE and the sample specific gravity: e.g. Gentner [12], reporting on Picea sitchensis, found $r^{2}=0.45$, and Choi [6], reporting on Pseudotsuga menziesii, found $r^{2}=0.54$, both with latewood density. Takata and Hirakawa [28], on Larix kaempferi, found $r^{2}=0.55$ with a mean ring density and $r^{2}=0.54$ with latewood percentage. On Pseudotsuga menziesii, in Part I of this report, the authors found $r^{2}=0.37$ with latewood width. McKimmy [18], on Pseudotsuga menziesii, found that earlywood density was more related to strength properties than latewood density: MOE is dependent on the stiffest wood in the ring (i.e. latewood), while strength is dependent on the weakest wood in the ring, where fracture starts (i.e. earlywood).

All used within-ring density parameters based on an earlywood-latewood boundary. It is clear that, with regard with the MOE-density relationship, these parameters are not more relevant than the mean density (or the specific gravity) of the sample. On the other hand, complete density profile contains a huge amount of data (within-ring local density variability) which are ignored when summing up a whole ring or a whole profile with mean density. Thus, we question whether the early- wood-latewood model is the best way to sum up the information enclosed in a density profile.

The aim of this study is to attempt to better explain the MOE variations using the data contained in a density profile. A first step toward this was complied by Mamdy et al. ([17] and Part I of this report). They found a highly significant relationship among trunk (and board) MOE and parameters of polynomials describing the density variations of a given ring density segment. This segment was mainly located in the latewood. Values of $r^{2}$ ranged from $0.58, P<0.001$ to $0.80, P<0.001$, according to the number of polynomial coefficients involved in the relationship. However, the polynomial coefficients have no evident biological and physical meaning. Therefore, in this report, we try to model the relationships among trunk, board and standard samples MOE and some simple parameters derived from microdensity profiles with a simple biological meaning, not established on the earlywood-latewood limit.

Another explanation for the lack of accuracy of the models describing the MOE-density relationship is that the mathematical shape and/or the parameters of the models used to outline this relationship may be different from one genetic unit to another. Various authors noted that the growth rate-wood density relationship on Picea abies [5, 26] and Picea mariana [31] was significantly different from one genetic unit to another. Hence, and for standard sample MOE only, we will try to answer the question "Is there genetic control for the relationship between MOE and density parameters?" If yes, this genetic variation could be used by the tree breeder to select genetic units with more favourable relationships.

\section{MATERIALS AND METHODS}

Plant material and study data are described in Part I of this report. Figure 1 illustrates the samples and the measurements. For the trunk MOE study only, two types of profiles were used: the microdensity profile, i.e. the evolution from pith to bark of the local density, and the evolution from pith to bark of 'density $\times 2 \pi$ radius' (weighted density profile), which gives an estimation of the biomass produced by the cambium during each growth period (figure 2).

Results from numerous authors $[6,12,16,28]$ suggest that, in the frame of the earlywood-latewood modelling of the ring density profile, the most relevant part of the ring is the latewood. Figure 3 shows two density profiles, one from a stiff sample, and the other from a flexible one. It is clear on this example that there is more 'high density wood' (latewood) in the stiff than in the flexible sample. It is evident both on heuristic reasoning 


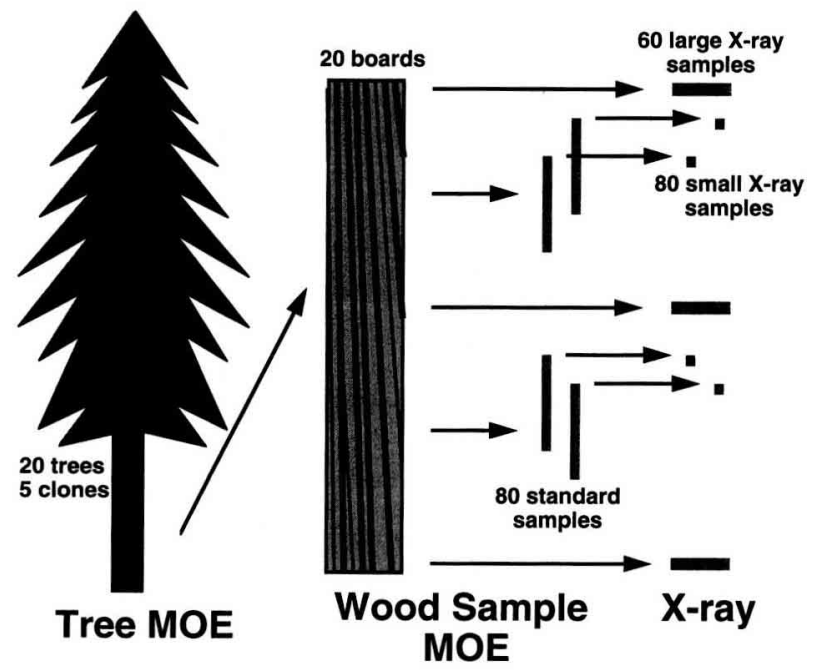

Figure 1. Presentation of the samples and measurements.

density profile

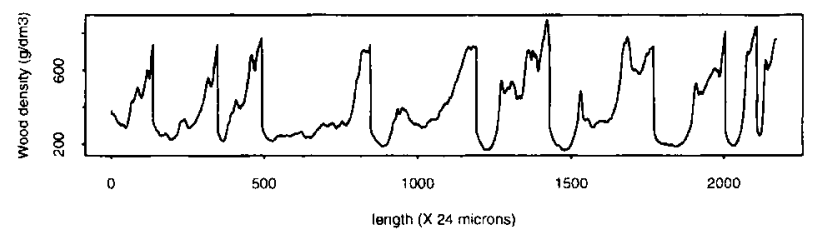

weight increment profile

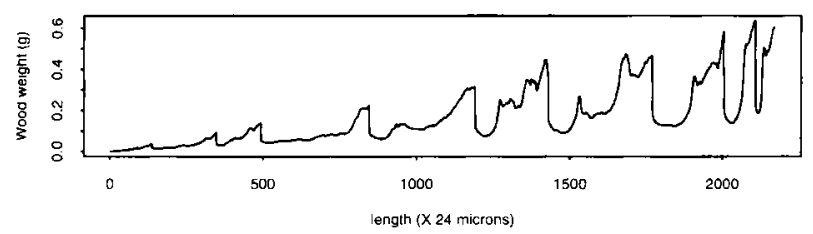

Figure 2. Upper panel: a raw density profile. Lower panel: a weighted density profile. The weight is proportional to the volume of the wood sheath correspondent to the local density profile value. We assume that the stem shape is cylindrical.

and on this example that MOE might be related to the amount of latewood within a sample. However, as the earlywood-latewood boundary is a physiological limit, based on Mork's principle [19] that helps to locate in the ring the point where the cambium activity changes abruptly during the growing season, there is no a priori reason why MOE should be related to that boundary. The MOE-density relationship is, in this example, a mechanical relationship. Therefore, we based our study
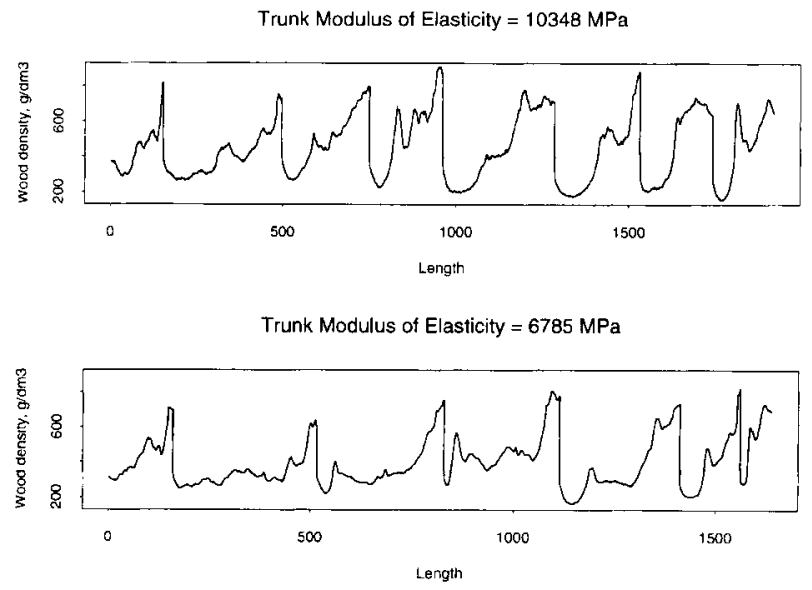

Figure 3. Upper panel: density profile of a stiff tree. Lower panel: density profile of a flexible tree. It is clear that the amount of 'high density wood' is larger in the stiff than in the flexible profile.

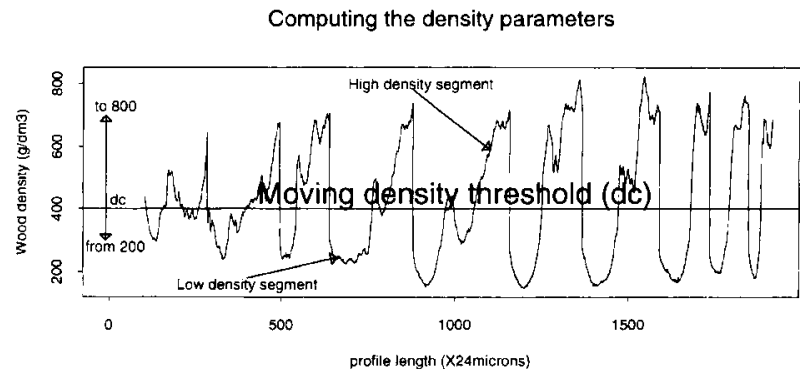

Figure 4. The study density parameters were computed according to a moving density criterion (dc) threshold. This threshold divides the complete density profile into two 'high density' and 'low density' segments.

on an exhaustive search of the location of high density wood.

First, using a moving density criterion (dc), the complete profiles were divided into two parts: high density and low density segments, according to the local density compared to dc (figure 4). The dc parameter ranged from 200 to $800 \mathrm{~g} \cdot \mathrm{cm}^{-3}$ (step $10 \mathrm{~g} \cdot \mathrm{cm}^{-3}$ ). Then, for each dc value, the following parameters were computed: mean densities and length of both high and low density segments (respectively, Dhi, Dlo, Lhi and Llo, which may be seen as a prolongation of the earlywood-latewood densities and width), cumulated density for the high density segment (Dcu), energy (Ene) and number of crossing points between the dc line and the profile $(\mathrm{Nb})$. 
Mean density of the high and low density segments (Dhi and Dlo)

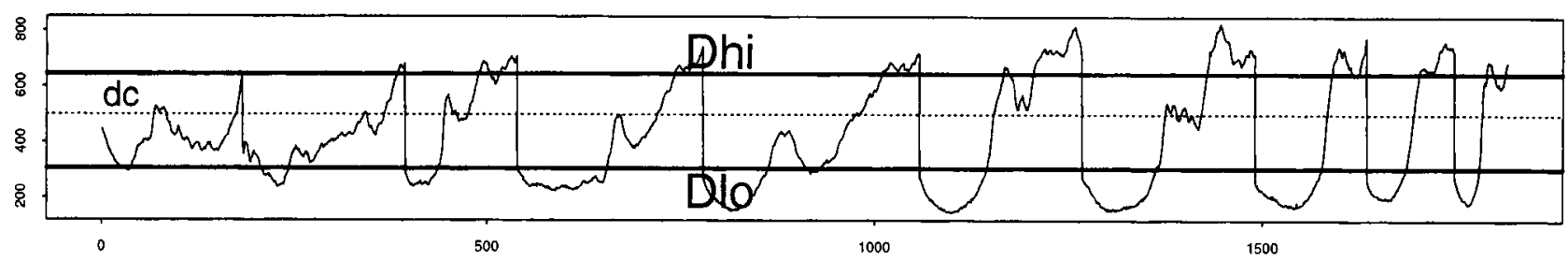

Length of the low density segment and number of intersections (Llo and $\mathrm{Nb}$ )

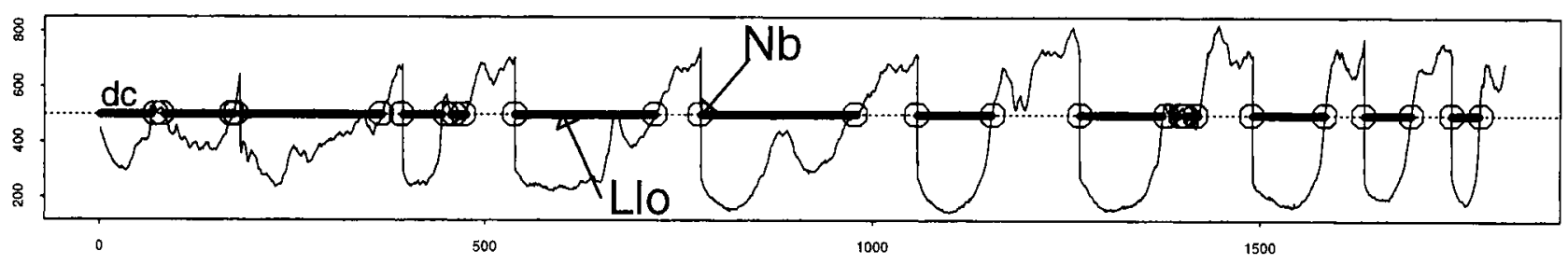

The profile energy (Ene)

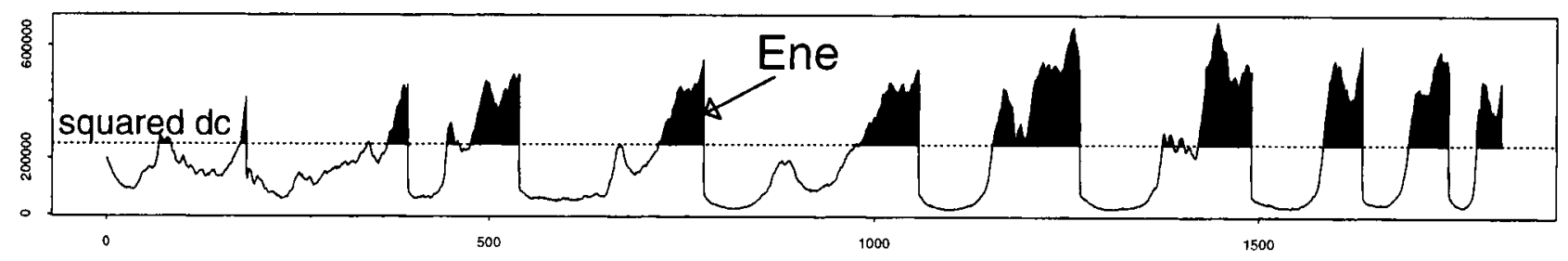

Figure 5. The five density parameters of the study are shown in this figure. On the top profile, Dhi is the mean density of the high density segment, and Dlo is the mean density of the low density segment. On the middle profile, Llo is the length of the low density segment, and $\mathrm{Nb}$ is the number of intersections between the density profile and the moving density criterion (dc) threshold. On the bottom profile, the energy (Ene) is the surface between the squared profile and the squared dc threshold.

Figure 5 illustrates these parameters. Dcu is the surface between the dc threshold and the high density segment of the profile. The energy (Ene) of a density profile $x_{i}$ is $\sum_{i=1}^{n} x i^{2}$, and is a parameter commonly used in signal treatment (Trubuil, personal communication). For density values of dc over $500-600 \mathrm{~g} \cdot \mathrm{dm}^{-3}, \mathrm{Nb}$ is twice the number of high density peaks in the profile (latewood peaks and false rings).

To investigate the possible redundancy of the density parameters, a correlation study was conducted among them. For boards and standard samples density profiles, three parameters are very strongly related $\left(r^{2}>0.99\right.$, $P<0.001$, whatever the study level): Lhi, Dcu and Ene. Thus two of them, Lhi and Dcu, were excluded from the study of the modelling of the boards and of the standard
Table I. Samples and corresponding variables.

\begin{tabular}{lc}
\hline Sample & Variable \\
\hline $\begin{array}{l}\text { Trunk, board, standard sample } \\
\text { Density profile }\end{array}$ & MOE \\
\hline
\end{tabular}

samples MOE (but not from the trunk MOE study, where the used profiles were the biomass profiles). Table I shows the samples and the corresponding variables.

A correlation study (using Pearson's linear correlation coefficient) and a multiple linear regression study (using the stepwise efroymson method [27]) were then conducted among all the density parameters and the MOE at all sample and genetic units levels. 


\subsection{Relationships between MOE and density parameters at different levels (sample type)}

For each density parameter and each type of sample the optimum dc level was noted: this optimum level is the dc value for which the $r^{2}$ of the single relationship between the density parameter and the MOE is maximum. Figure 6 shows an example of the evolution of the $r^{2}$ of the relationship between the MOE and one parameter, Ene, when dc varies from 200 to $800 \mathrm{~g} \cdot \mathrm{dm}^{-3}$.

\subsection{Genetic control of the MOE-density relationship}

For the standard samples, for each clone, simple and multiple linear regression studies were conducted clone by clone. For the multiple relationship, the number of explanatory variables was reduced from five to a maximum of two. Then a second multiple linear regression was conducted, imposing the same mathematical model (fixing the same two parameters for all the clones).

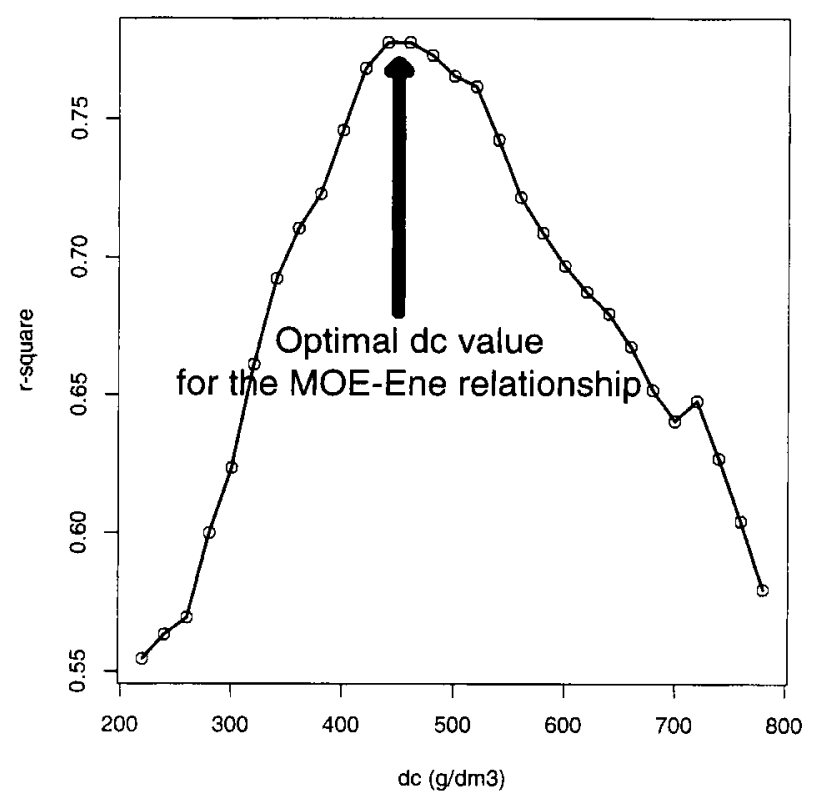

Figure 6. The selection of the optimal moving density criterion (dc) value for a given density parameter (here, energy [Ene]). The line shows the evolution of the strength of the relationship between the modulus of elasticity (MOE) and the parameter when the $\mathrm{dc}$ threshold varies from 200 to $800 \mathrm{~g} \cdot \mathrm{dm}^{-3}$. The optimal dc value coincides with the maximum $r^{2}$.

\section{RESULTS}

\subsection{The trunk MOE and density parameters relationships}

The correlation coefficients are maximum for the parameters calculated from the weighted density profiles recorded on the samples collected at $2 \mathrm{~m}$ high in the stems. Quite high single relationships were found between MOE and, respectively, Nb $\left(r^{2}=0.58\right.$, $P<0.001)$ and Lhi $\left(r^{2}=0.49, P<0.001\right)$. Table Il gives the complete results for the single relationships.

\subsection{The board MOE and density parameters relationships}

The correlation coefficients are maximum for the parameters calculated from the density profiles recorded on the samples collected at $1.3 \mathrm{~m}$ high in the stems. High single relationships were found between MOE and, respectively, Ene $\left(r^{2}=0.78, P<0.001\right), \mathrm{Nb}\left(r^{2}=0.71\right.$, $P<0.001)$ and Dhi $\left(r^{2}=0.66, P<0.001\right)$ (table III).

Table II. The best single relationships between the trunk modulus of elasticity and the density parameter.

\begin{tabular}{lccc}
\hline Density parameters & $\mathrm{dc}\left(\mathrm{g} \cdot \mathrm{dm}^{-3}\right)$ & $r^{2}$ & $P$ \\
\hline Dhi & 300 & 0.18 & 0.0943 \\
Dlo & 740 & 0.15 & 0.0961 \\
Lhi & 620 & 0.49 & 0.0006 \\
Llo & 420 & 0.28 & 0.0165 \\
Dcu & 600 & 0.28 & 0.0161 \\
Ene & 800 & 0.24 & 0.0284 \\
Nb & 660 & 0.58 & $\mathbf{0 0 2 8 4}$
\end{tabular}

Table III. The best single relationships between the board modulus of elasticity (MOE) and the density parameters, according to the moving density criterion (dc).

\begin{tabular}{lccc}
\hline Density parameters & $\mathrm{dc}\left(\mathrm{g} \cdot \mathrm{dm}^{-3}\right)$ & $r^{2}$ & $P$ \\
\hline Dhi & 220 & 0.66 & $<0.001$ \\
Dlo & 780 & 0.64 & $<0.001$ \\
Llo & 400 & 0.32 & 0.0094 \\
Ene & 450 & 0.78 & $<0.001$ \\
Nb & 710 & 0.71 & $<0.001$ \\
\hline
\end{tabular}




\subsection{The standard sample MOE and density parameters relationships}

We studied the quality of a linear regression among, on the one hand, the MOE, and on the other hand, the parameters of the previous section. This was done successively on the 80 samples, 40 top samples and clone by clone (eight top samples per clone).

We found that for all 80 samples, whatever the density level, the strength of the relationship is low. The maximum values were found for Dlo $\left(r^{2}=0.22, P<0.001\right)$ and Dhi $\left(r^{2}=0.17, P<0.001\right)$ (table $\left.I V\right)$.

For the 40 top samples, $r^{2}$ strongly increased. The maximum values, still moderated, were found for Dhi $\left(r^{2}=0.48, P<0.001\right)$, Dlo $\left(r^{2}=0 ., P<0.001\right)$ Llo $\left(r^{2}=0.37, P<0.001\right)$, Llo $\left(r^{2}=0.40, P<0.001\right)$ (table V).

\subsection{Genetic effects on the standard samples MOE and density parameters relationships}

Clone by clone, the relationships between MOE and the density parameters were always stronger when the samples were only those from the upper part of the stem.

Table IV. The best single relationships between the 80 standard sample modulus of elasticity (MOE) and their density parameters.

\begin{tabular}{lccc}
\hline Density parameters & $\mathrm{dc}\left(\mathrm{g} \cdot \mathrm{dm}^{-3}\right)$ & $r^{2}$ & $P$ \\
\hline Dhi & 360 & 0.17 & 0.0002 \\
Dlo & 420 & 0.22 & $<0.001$ \\
Llo & 670 & 0.08 & 0.0096 \\
Ene & 660 & 0.09 & 0.0085 \\
$\mathrm{Nb}$ & 690 & 0.15 & 0.0004 \\
\hline
\end{tabular}

Table V. The best single relationships between the 40 top standard sample modulus of elasticity (MOE) and their density parameters.

\begin{tabular}{lccc}
\hline Density parameters & $\mathrm{dc}\left(\mathrm{g} \cdot \mathrm{dm}^{-3}\right)$ & $r^{2}$ & $P$ \\
\hline Dli: & 340 & 0.48 & $<0.001$ \\
Dlo & 420 & 0.40 & $<0.001$ \\
Llo & 640 & 0.37 & $<0.001$ \\
Ene & 640 & 0.42 & $<0.001$ \\
Nb & 730 & 0.38 & $<0.001$ \\
\hline
\end{tabular}

All clones had high or very high values of $r^{2}$ (close to and over 0.7$)$ : clone $1453\left(r^{2}=0.69, P<0.05\right)$ clone $1439\left(r^{2}=0.81, P<0.001\right.$ for NB), clone 1489 $\left(r^{2}=0.79, P<0.001\right.$ for Llo and $0.71, P<0.001$ for $\mathrm{Nb}$ ), clone $1464\left(\mathrm{r}^{2}=0.84, P<0.001\right.$ for NB and $r^{2}=0.70$, $P<0.01$ for Dhi $)$ and clone $1483\left(r^{2}=0.94, P<0.001\right.$ for Llo, $r^{2}=0.84, P<0.001$ for Lhi, $r^{2}=0.81$, $P<0.001$ for Dlo and $r^{2}=0.78, P<0.001$ for Dc). Complete results are presented clone by clone in tables $V I$ to $X$.

Table VI. Clone 1483, the best single relationships between the eight top sample modulus of elasticity (MOE) and the corresponding density parameters.

\begin{tabular}{lccc}
\hline Density parameters & $\mathrm{dc}\left(\mathrm{g} \cdot \mathrm{dm}^{-3}\right)$ & $r^{2}$ & $P$ \\
\hline Dhi & 380 & 0.57 & 0.0296 \\
Dlo & 680 & 0.94 & 0.0001 \\
Llo & 460 & 0.81 & 0.0025 \\
Ene & 480 & 0.71 & 0.0088 \\
$\mathrm{Nb}$ & 660 & 0.65 & 0.0161 \\
\hline
\end{tabular}

Table VII. Clone 1464, the best single relationships between the eight top sample modulus of elasticity (MOE) and the corresponding density parameters.

\begin{tabular}{lccc}
\hline Density parameters & $\mathrm{dc}\left(\mathrm{g} \cdot \mathrm{dm}^{-3}\right)$ & $r^{2}$ & $P$ \\
\hline Dhi & 350 & 0.70 & 0.0093 \\
Dlo & 420 & 0.53 & 0.0400 \\
Llo & 730 & 0.67 & 0.0128 \\
Ene & 730 & 0.66 & 0.0485 \\
$\mathrm{Nb}$ & 740 & $\mathbf{0 . 8 6}$ & $\mathbf{0 . 0 0 1 0}$ \\
\hline
\end{tabular}

Table VIII. Clone 1489, the best single relationships between the eight top sample modulus of elasticity (MOE) and the corresponding density parameters.

\begin{tabular}{lccc}
\hline Density parameters & $\mathrm{dc}\left(\mathrm{g} \cdot \mathrm{dm}^{-3}\right)$ & $r^{2}$ & $P$ \\
\hline Dhi & 500 & 0.32 & 0.1422 \\
Dlo & 420 & 0.21 & 0.2487 \\
Llo & 680 & 0.79 & 0.0032 \\
Ene & 700 & 0.47 & 0.0877 \\
$\mathrm{Nb}$ & 430 & 0.71 & 0.0090 \\
\hline
\end{tabular}


Table IX. Clone 1439, the best single relationships between the eight top sample modulus of elasticity (MOE) and the corresponding density parameters.

\begin{tabular}{lccc}
\hline Density parameters & $\mathrm{dc}\left(\mathrm{g} \cdot \mathrm{dm}^{-3}\right)$ & $r^{2}$ & $P$ \\
\hline Dhi & 480 & 0.72 & 0.0076 \\
Dlo & 530 & 0.46 & 0.0656 \\
Llo & 670 & 0.27 & 0.1831 \\
Ene & 760 & 0.60 & 0.0239 \\
Nb & 730 & $\mathbf{0 . 8 1}$ & $\mathbf{0 . 0 0 2 5}$ \\
\hline
\end{tabular}

Table X. Clone 1453, the best single relationships between the eight top sample modulus of elasticity (MOE) and the corresponding density parameters.

\begin{tabular}{lccc}
\hline Density parameters & $\mathrm{dc}\left(\mathrm{g} \cdot \mathrm{dm}^{-3}\right)$ & $r^{2}$ & $P$ \\
\hline Dhi & 650 & 0.52 & 0.0443 \\
Dlo & 390 & 0.49 & 0.0523 \\
Llo & 700 & 0.18 & 0.2889 \\
Ene & 740 & 0.69 & 0.0105 \\
$\mathrm{Nb}$ & 350 & 0.51 & 0.0463 \\
\hline
\end{tabular}

Table XI. The best multiple relationship between the trunk modulus of elasticity (MOE) and the density parameters.

\begin{tabular}{lcccc}
\hline Sample & Ene & $\mathrm{Nb}$ & $r^{2}(1)$ & No. of param. \\
\hline Trunks $(n=20)$ & $\mathbf{X}$ & $\mathbf{X}$ & 0.66 & 2 \\
\hline
\end{tabular}

(1) $P$ always under 0.001 .

\subsection{Best models (multiple linear relationships) relating MOE and wood density parameters}

Tables XI and XII show the parameters involved $(\mathbf{X})$ in the best multiple linear relationships (according to the stepwise efroymson method [27] and the associated adjusted multiple $r^{2}$, respectively, for the trunk MOE (table $X I$ ) and the boards and standard samples MOE (table XII). The coefficient of determination is maximum for upper stem samples and within-clone models.

Table XIII presents the best multiple linear models for the five clones, without any condition fixed for the choice of the parameters. Parameters involved in the models are very different from clone to clone. With our study parameters, it seems difficult to select one model mathematical form suitable to all the clones.

Table XIV gives the results of an attempt to select only one mathematical form common to all five clones. It contains the best multiple linear models for these five clones, with the mathematical shape of the model fixed as follows: $\mathbf{M O E}=\mathrm{a}+\mathrm{b} . \boldsymbol{D l o}+\mathrm{c} . \mathbf{N b}$. Estimated values of the model parameters are very different from one clone to the other. Clone 1453 in particular is very different from the four other clones from that point of view. The $r^{2}$ square value of that clone model $(0.56)$ is relatively low, compared to that in table XII (0.95).

\section{DISCUSSION AND CONCLUSION}

It is possible to calculate simple biological parameters strongly or very strongly related to trunk, board or standard sample MOE. These relationships are stronger than those among MOE and within-ring classical parameters based on the earlywood-latewood model (for trunk and

Table XII. The best multiple relationship between the boards and the standard sample modulus of elasticity (MOE) and the density parameters.

\begin{tabular}{lccccccc}
\hline Sample & Dhi & Dlo & Llo & Ene & Nb & $r^{2}(1)$ & No. of param. \\
\hline Boards $(n=20)$ & & & $\mathbf{X}$ & $\mathbf{X}$ & & 0.84 & 2 \\
All standard samples $(n=80)$ & & & $\mathbf{X}$ & & $\mathbf{X}$ & 0.25 & 2 \\
Standard samples from upper stem $(n=40)$ & $\mathbf{X}$ & & & & $\mathbf{X}$ & 0.51 & 2 \\
Clone 1483 $(n=8)$ & & $\mathbf{X}$ & & & & 0.94 & 1 \\
Clone 1464 $(n=8)$ & & $\mathbf{X}$ & & & $\mathbf{X}$ & 0.90 & 2 \\
Clone 1489 $(n=8)$ & & $\mathbf{X}$ & & $\mathbf{X}$ & 0.85 & 2 \\
Clone 1439(n=8) & $\mathbf{X}$ & & & $\mathbf{X}$ & 0.88 & 2 \\
Clone 1453 $(n=8)$ & & & $\mathbf{X}$ & $\mathbf{X}$ & 0.95 & 2 \\
\hline
\end{tabular}

(1) $P$ always under 0.001 
Table XIII. The best multiple linear models for the five clones, without any condition fixed for the choice of the parameters.

\begin{tabular}{ll}
\hline Clone 1483 & MOE $=-13179+56 . \mathrm{Dlo}$ \\
Clone 1464 & $\mathrm{MOE}=11855-15 . \mathrm{Dlo}+391 . \mathrm{Nb}$ \\
Clone 1439 & $\mathrm{MOE}=15169-22 . \mathrm{Dlo}+772 . \mathrm{Nb}$ \\
Clone 1489 & $\mathrm{MOE}=43275-51 . \mathrm{Llo}+444 . \mathrm{Nb}$ \\
Clone 1453 & $\mathrm{MOE}=12034-1712.10^{4}$. Ene $+620 . \mathrm{Nb}$ \\
\hline
\end{tabular}

Table XIV. The best multiple linear models for the five clones, with the mathematical shape of the model chosen as follows: $\mathbf{M O E}=\mathrm{a}+\mathrm{b} . \mathrm{Dlo}+\mathrm{c} . \mathrm{Nb}$

\begin{tabular}{lcccc}
\hline Clones & $\mathrm{a}$ & $\mathrm{b}$ & $\mathrm{c}$ & $\mathrm{r}^{2}$ \\
\hline 1483 & 15649 & -15.7 & 62.4 & 0.81 \\
1464 & 11855 & -15.1 & 391.1 & 0.90 \\
1439 & 15169 & -22 & 771.6 & 0.88 \\
1489 & 9662 & -20.3 & 892.7 & 0.76 \\
1453 & -5946 & 56.3 & 496.7 & 0.56 \\
\hline
\end{tabular}

board respectively, $0.42, P<0.01$ and $0.37, P<0.01$ in [16], $0.58, P<0.001$ and $0.78, P<0.001$ in this study; tables $I I$ and $I I I)$.

The high relationship between Ene (sum of the squared densities) and board MOE suggests that the relationship between local MOE and density is non-linear such as that noted by Chantre [4] on Norway spruce. This could mean that the increase in density in the latewood is not only related with a decrease of the porosity, but also with an increase of the cell wall MOE, itself linked with a smaller microfibril angle (Fournier-Djimbi, personal communication).

In a bending test, if strength direction is perpendicular to the ring limits, the outer layers play a greater role than inner layers $[2,10]$. That is certainly why the trunk MOE-density relationship is stronger for parameters from biomass profiles (radius ${ }^{2}$ weighted) than for parameters from density profiles. Weighing density with radius $^{3}$ was also tried (thus assuming that the outer layers' influence was not linked to their mass, but rather to their rotation inertia); however, this did not improve the relationships.

For the standard samples, the general relationship between MOE and density parameters is far stronger $\left(r^{2}\right.$ from 0.22 to 0.48 ; tables $I V$ and $V$ ) when excluding the bottom standard samples. Thus, the MOE of a $36 \mathrm{~cm}$ long standard sample taken just over the stump cannot be accurately explained by density parameters of the same sample. Systematic higher compression wood content in the stem part under $1 \mathrm{~m}$ from the ground could lead to an interpretation. Timell [29], however, stated that results are contradictory when researchers try to answer the question of whether compression wood occurs more frequently in the lower part of the stem. Zobel and colleagues $[32,33]$ wrote that in a zone approximately 0.5 to $1 \mathrm{~m}$ from the ground line, wood is very erratic and non-uniform, and not representative of the tree. Larson [14] noted that cells in stump wood show distortion in radial alignment, with regard with cells in stem wood, and that wavy grain and whirled grain occur more frequently in or near the stump than higher in the stem. Hence, we can conclude that variation within a sample taken near the stump is larger than that of the same sample taken near or over breast height. Such a sample density structure will not be accurately estimated from that of a thin wood specimen taken at one of its ends. It is therefore clear that the sample location within the tree is important and has to be known.

Combining the best parameters in multiple linear relationships is a technique to explain from 25 to $95 \%$ of the natural variability for MOE. For standard samples, one parameter seems to be more interesting than the others $\mathrm{Nb}$, found respectively in seven of nine multiple relationships. This parameter is twice the number of high density peaks in the density profile segment. It is therefore related to both the number of false rings, and the number of rings (itself very closely related with the ring width) in the samples. However, most parameters involved in the relationships are different for trunks, boards, standard samples and standard samples at clone level (not the same number of parameters, not the same parameters, not the same dc density threshold for the same parameters, except maybe for $\mathrm{Nb}$, for which the $\mathrm{dc}$ value is nearly always between 660 and $740 \mathrm{~g} \cdot \mathrm{dm}^{-3}$ ). The clonal models are always far more precise than the general model, and the best multiple linear relationship differs from one clone to another. Trying to fix a given mathematical shape for the multiple linear model decreases the precision of two or three of five clonal models. No attempt has been made to determine if this precision decrease was significant.

The clone 1453 model is completely different from the other four. The MOE of this clone is negatively (and significantly, $P<0.05$ ) related to Dhi and Ene, while the same relationships are positive at all others levels.

Hence, the microdensity profile can explain most of the MOE variation. The density profiles used in the models at stem and board levels are the same. They come from samples sawn in the boards. Therefore, they are likely to better describe density variations in the board than in the complete stem. That is certainly why the 
MOE-density-parameters relationship is stronger for the boards than for the stem.

Genetic variation for the relationships between wood properties and growth traits have recently been found at different genetic levels (e.g. [4, 26, 31]). In this study, clonal models are far more precise than general models, and are different from one clone to another: for this reason we assert that there is a strong genetic effect on the relationship between density and MOE. It means that genetic units could build their stiffness in different ways.

Taking this genetic effect into account could be a way to increase the accuracy of models relating mechanical properties and density.

Breeders may use the differences among the models as secondary traits for selection and some ways to build wood stiffness could be better than others.

This study proves that simple wood density parameters can explain, for the most part, the natural variation for MOE. Nevertheless, these parameters may not be the most relevant ones to describe the genetic effect on the study relationships. They are closely related to each other. Using parameters derived from models calculated using advanced techniques such as wavelet modelization, and/or other parameters than density parameters (grain angle, Nepveu, personal communication, microfibril angle, [3]) may be a more efficient and objective way to determine what will, in a density profile, explain the stiffness of a piece of wood.

Another way to increase modelling efficiency could be to imagine and test physical models based on hypotheses about the relationships between local MOE and local wood density, and then compare them to the statistical models of our study.

These results were obtained on only five clones and 20 trees. Although conclusions were drawn using only statistically highly significant parameters, new studies using more clones and more trees per clone would be greatly beneficial.

Acknowledgements: We wish to warmly thank Frédéric Millier, Daniel Lacan, Dominique Veisse and Patrick Poursat, Inra research technicians, for their very valuable help and comments all along this study.

\section{REFERENCES}

[1] Armstrong J.P., Skaar C., de Zeeuw C., The effect of specific gravity on several mechanical properties of some world woods, Wood Sci. Technol. 18 (2) (1984) 137-146.

[2] Bodig J., Jayne B., Mechanics of Wood and Wood Composites, Van Nostrand Reinhold Co., New York, 1982.
[3] Cave I.D., Walker J.C.F., Stiffness of wood in fastgrown plantation softwoods - the influence of the microfibril angle, For. Prod. J. 44 (5) (1994) 43-48.

[4] Chantre G., Liaison entre rigidité et densité du bois à l'intérieur du cerne. Application au cas de l'épicéa commun (Picea abies Karst.), rapport de DEA sciences du bois, INPL Nancy, France, 1989, 46 p.

[5] Chantre G., Gouma R., Influence du génotype, de l'âge et de la station sur la relation entre l'infradensité du bois et la vigueur chez l'épicéa commun (Picea abies Karst.), Ann. Rech. Sylv. 1993-1994. AFOCEL, France, 1994.

[6] Choi A.S.C., Correlation between mechanical strength of wood and annual ring characteristics in Douglas-fir juvenile and mature wood, Master of Science thesis, Oregon State University, OR, 1986, 84 p.

[7] Clauson M.L., Wilson J.B., Comparison of video and xray for scanning wood density, For. Prod. J. 41 (3) (1991) $58-62$.

[8] Collardet J., Besset J., Bois commerciaux. Tome I. Les résineux (conifères), Editions $\mathrm{H}$. Vial et Centre technique du bois et de l'ameublement, Paris, France, 1988, 277 p.

[9] de Reboul L., Influence de la croissance et de l'âge des arbres sur le module de rigidité du bois en flexion statique, Ann. Sylv. AFOCEL, Paris, France, 1994, pp. 347-378.

[10] Fournier M., Méchanique de l'arbre sur pied : poids propre, contraintes climatiques et maturation dans la tige standard, thèse, INP de Lorraine, Sciences du bois, France, 1989.

[11] Garland H., A microscopic study of coniferous wood in relation to its strength properties, Annals of the Missouri Botanical Garden 26 (1) (1939) 1-95.

[12] Gentner R., Appréciation non destructive de la qualité du bois d'arbres sur pied : cas de l'épicéa de Sitka (Picea sitchensis (Bong.) Carr.), rapport ERQB Inra Nancy, ENITEF, France, 1985, $98 \mathrm{p}$.

[13] Koizumi A., Ueda K., Estimation of the mechanical properties of standing trees by non-destructive bending tests, Mokuzai Gakkaishi 39 (2) (1986) 669-676.

[14] Larson P., The Vascular Cambium, Springer-Verlag, Berlin, 1994, 725 p.

[15] Littleford T.W., Variation of strength properties within trees and between trees in a stand of rapid-growth Douglas-fir, For. Prod. Lab. Can. Vancouver, Canada, 1961.

[16] Mamdy C., Contribution à l'étude du module d'élasticité de troncs d'arbres sur pied; utilisation en amélioration génétique des arbres forestiers, rapport de DEA Matière condensée et diluée, ESEM Orléans, Inra Orléans, France, 1995, p. 47.

[17] Mamdy C., Rozenberg P., Franc A., Schermann N., Bastien J.C., Modulus of elasticity of standing Douglas fir trees, use of the modulomètre in a tree breeding study, Joint meeting of the IUFRO working parties S.02.05, 12 and 14, 1-4 August 1995, Limoges, France, 1995.

[18] McKimmy M.D., The effect of intra-ring microcharacteristics on mechanical properties of young-growth Douglas-fir wood. Fifth Symposium on Non-destructive Testing of Wood, Washington State University, Seattle, WA, 1985. 
[19] Mork E., Die Qualitat des Fichtenholzes unter besonserer Ruckensichtnahme auf Scheif- und Papierholz, Papierfabrikant 26 (48) (1928) 741-747.

[20] Nepveu G., La variabilité du bois in le matériau bois, 2e édn., ARBOLOR, Nancy, 1991.

[21] Newlin J.A., Wilson T.R.C., The relation of the shrinkage and strength properties of wood to its specific gravity, USDA Bull. 676 (1919) $35 \mathrm{p}$.

[22] Panshin A.J., de Zeeuw C., Textbook of Wood Technology, McGraw-Hill Book Co., New York, 1980, 722 p.

[23] Pâques L., Rozenberg P., Intraspecific variability of European larch for wood properties: preliminary results, in: Proc. 'Larch Genetics and Breeding', IUFRO Working Party S2.02-07, Sweden, 1995, pp. 21-33.

[24] Polge H., Etablissement des courbes de variation de la densité du bois par exploration densitométrique de radiographies d'échantillons prélevés à la tarière sur des arbres vivants. Application dans les domaines technologiques et physiologiques, thèse de doctorat, Université de Nancy, France, 1966, $206 \mathrm{p}$.

[25] Quanci M.J., Mechanical, physical, and anatomical properties of short-rotation Douglas-fir and white ash, thesis, Purdue University, USA, 1988, 211 p.
[26] Rozenberg P., Van de Sype H., Genetic variation of the Pilodyn-girth relationship on Norway spruce (Picea abies L.(Karst.)). Ann. Sci. For. 53 (1996) 1153-1 166.

[27] Statistical Sciences, S-PLUS Guide to Statistical and Mathematical Analysis, Version 3.2, Seattle, StatSci, a division of MathSoft, Inc., 1993.

[28] Takata K., Hirakawa Y., Variation in growth parameters among Japanese larch from different provenances, Third PRWA Conference, Faculty of Agriculture, Kyushu University, Japan, 1995.

[29] Timell T.E., Compression Wood in Gymnosperms, 3 vols., Springer-Verlag, Berlin, 1986, $2150 \mathrm{p}$.

[30] Zhang S.Y., Effect of growth rate on wood specific gravity and selected mechanical properties in individual species from distinct wood categories, Wood Sci. Technol. 29 (1995) $451-465$.

[31] Zhang S.Y., Simpson D., Morgenstern E.K., Variation in the relationship of wood density with growth in 40 black spruce (Picea mariana) families grown in New Brunswick, Wood Fiber Sci. 28 (1) (1996) 9l-99.

[32] Zobel B.J, Van Buijtenen J.P., Wood Variation: Its Causes and Control, Springer-Verlag, Berlin, 1989, 363 p.

[33] Zobel. B.J, Jett B.J., Genetics of Wood Production, Springer-Verlag, Berlin, 1995, 337 p. 